\title{
Hour Times Picomole Per Liter Per Milligram Per Gram
}

National Cancer Institute

\section{Source}

National Cancer Institute. Hour Times Picomole Per Liter Per Milligram Per Gram. NCI

Thesaurus. Code C117932.

Hour times picomole per liter, divided by milligram per gram. 